\title{
The Oral Text as a Translator of Ancient Linguoculture of the Northern Angara Region
}

\author{
Olga V. Felde* \\ Siberian Federal University \\ 79 Svobodny, Krasnoyarsk, 660041, Russia
}

Received 05.12.2018, received in revised form 28.12.2018, accepted 11.01.2019

The article deals with the oral Siberian text as the most important unit of regional linguoculturea holistic and heterogeneous linguo-cognitive phenomenon defined by cultural codes and subcodes (anthropomorphic, biomorphic, theological, mythological), spatial coordinates, dominant values and social experience of the local community.

The linguisticmeans representing the emotional, sensual, ethical, aesthetic experience of Angara Siberians, as well as methods and means of explication of the mythologicalconceptualization of the world are identified and analyzed.

The study is conducted on the basis of oral texts, mostly personalized narratives, written by the author of the article during the folklore-dialectological expeditions to the villages of the Northern Angara region founded by Russians in the XVII-XVIII centuries.

It was concluded that the oral Angara text reflects the cultural ideas and knowledge of Russian Siberians about man, society, nature, the infernal world.

The images and stereotypes presented in the oral Angara text are transmitted to the next generations via everyday communication, ensure the stability of worldview attitudes and contribute to preserving the identity of the ancient Siberian culture.

Keywords: Northern Angara region, regional linguoculture, cultural code, oral text, narration, emotive, affective, connotative, expressive, image of the world, world conceptualization.

The study was conducted with the financial support of the Russian Foundation for Basic Research, the Government of the Krasnoyarsk Krai, Krasnoyarsk Regional Fund of Science within the framework of the research project No. 17-14-24008 'The electronic textual corpus of linguoculture of the Northern Angara region'.

Research area: philology.

Citation: Felde, O.V.(2019). The oral text as a translatorof ancient linguoculture of the Northern Angara region. J. Sib. Fed. Univ. Humanit. soc. sci., 12(1), 55-76. DOI: DOI: 10.17516/1997$1370-0380$.

(C) Siberian Federal University. All rights reserved

* Corresponding author E-mail address: feldeo@list.ru

This work is licensed under a Creative Commons Attribution-NonCommercial 4.0 International License (CC BY-NC 4.0). 


\section{Введение в проблему исследования (Introduction)}

Анализ диалектных и региолектных текстов как средства фиксации, хранения и передачи культуроносносных смыслов, а также изучение устных региональных текстов в свете теории лингвокультуры входит в число актуальных задач русистики. В ряде научных центров Российской Федерации создаются текстовые корпуса, материалы которых служат эмпирической базой для многоаспектного изучения фундаментальной проблемы «язык и культура», а также для решения многих других вопросов различных отраслей и направлений современного языкознания. Так, сотрудниками Центра по изучению народно-речевой культуры им. проф. Л.И.Баранниковой проводятся исследования саратовских говоров как целостных культурно-коммуникативных образований, выявляются доминанты традиционной сельской культуры речевого общения (Гольдин, 2002; Гольдин, Крючкова, 2010). Русистами Томской лингвистической школы изоморфизм языка и культуры рассматривается преимущественно в лингвоперсонологическом и междисциплинарном аспектах (Гынгазова, Иванцова, 2015; Банкова, Калиткина, 2001); в Региональном центре русского языка, фольклора и этнографии (г. Иркутск) делается акцент на лексикографической фиксации и этнолингвистическом описании сибирского старожильческого текста Прибайкальской Сибири (Афанасьева-Медведева, 2011, 2007-2017).

Филологи Сибирского федерального университета привлекают устные тексты разных жанров в качестве важнейшего источника исследования региональной лингвокультуры и транслятора её ценностных доминант (Васильев, 2018; Кайзер, Фельде, 2018; Смирнов, 2018; Фельде, 2014). Актуальность такого подхода обусловлена необходимостью описания форм организации региональной лингвокультуры, её единиц, общенациональных и региональных черт, а также условий и особенностей бытования и устной передачи следующим поколениям.

В задачи настоящей статьи входит рассмотрение устного регионального текста как транслятора русской старожильческой лингвокультуры Северного Приангарья.

Выбор в качестве объекта исследования устного ангарского текста продиктован прежде всего экстралингвистическими факторами. Строительство каскада гидроэлектростанций на Ангаре, запланированная индустриализация региона, приток населения из других частей Российской Федерации неизбежно приведут к оттеснению традиционной старожильческой лингвокультуры и русских ангарских говоров в зону риска. Именно поэтому устный ангарский текст, 
эксплицирующий лингвокультурные концепты, базовые ценности культуры, представляет большой научный интерес.

Территория Северного Приангарья расположена в нижнем течении Ангары и занимает 107540 квадратных километров. Освоение русскими этих богатых лесом, пушниной и золотом земель началось ещё в XVII - XVIII вв., но расселение здесь до сих пор носит очаговый характер. Транспортная инфраструктура северной и восточной частей Приангарья неразвита: отсутствуют автомобильные дороги круглогодичного действия, нет железных дорог. Связь между некоторыми населёнными пунктами осуществляются до сих пор автотранспортом по зимникам, а с наступлением весенних паводков - водным путём. На протяжении многих десятилетий это способствовало не только сохранению архаичных элементов в региональной культуре и говорах местного населения, но и формированию особого лингвокультурного пространства, которое, вслед за Е.В.Терентьевой, понимается нами как совокупность «этнолингвокультур, создающих устойчиво-динамичное единство лингвокультурной ситуации региона» (Терентьева, 2013: 184).

Лингвокультура Северного Приангарья попала в фокус исследования сравнительно недавно, когда диалектологи и фольклористы Сибирского федерального университета приступили к систематическому сбору диалектных и фольклорных данных в Кежемском, Богучанском и Мотыгинском районах Красноярского края. В настоящее время уже создан и активно пополняется «Электронный текстовый корпус лингвокультуры Северного Приангарья», который стал важнейшим информационным ресурсом для её многоаспектного исследования (URL: http://angara.sfu-kras.ru). Не смотря на имеющийся задел в изучении лингвокультуры Северного Приангарья, всё еще остается множество нерешённых проблем, в том числе и проблема теоретического осмысления региональной лингвокультуры.

Концептологическими основаниями настоящего исследования (theoretical framework) являются, во-первых, теория изоморфизма языка, культуры и этнического сознания, представленная в трудах по культурной антропологии, этнопсихолингвистике, лингвокультурологии (Andrade R., 1995; Casson R.W. (ed.); Леонтьев, 1993; Лотман, Успенский, 2000; Карасик, 1998; Красных, 2002); во-вторых, концепция онтологии лингвокультуры, сформулированная В.В.Красных. Ссылаясь на Ю.М.Лотмана, Б.Л. Успенского, В.Н.Телию и других известных учёных, автор выдвигает постулат о лингвокультуре как о оязыков- 
ленной культуре, т.е. оязыковленном мировидении и миропонимании, при этом понимая культуру как «пространство общей памяти, в пределах которого могут сохраняться, актуализироваться и в определенном смысле воспроизводиться общие тексты, общие феномены, общие смыслы, как некоторое «знание», которое регулирует деятельность человека, управляет переживаниями, действиями, всей жизненной практикой людей в рамках общения и взаимодействия в социальных группах, включая общество в целом» (Красных, 2013: 135). Будучи коммуникативными единицами высшего порядка, устные тексты передают знания и представления о духовных и социальных ценностях и стереотипах лингвокультурного сообщества.

\section{Постановка проблемы (Statement of the problem)}

Одной из отличительных особенностей современной когнитивно-коммуникативной макропарадигмы является интерес к национальным и региональным лингвокультурам. Разделяем мнение В.В.Красных о том, что они формируются «образами сознания в их вербальных одеждах» (Красных, 2013: 136). Именно поэтому изучение единиц и особенностей той или иной лингвокультуры - прямой путь к постижению внутреннего мира человека, а также процессов переживания и осмысления окружающей действительности представителями различных этнических, субэтнических и этносоциальных сообществ. Известна также точка зрения на лингвокультуру как «совокупность массива информации культуры, получившего объективацию в языке» (Федоров, 2014). Не вдаваясь в анализ приведённых выше определений, остановимся на том понимании региональной лингвокультуры, которое лежит в основе нашего исследования. Региональная лингвокультура - это целостный и одновременно гетерогенный лингвокогнитивный феномен, детерминированный национальными культурными кодами и субкодами (антропоморфным, биоморфным, теологическим, мифологическим, бытовым, промысловым и др.), а также пространственными координатами, ценностными доминантами и социальным опытом локального сообщества. Региональная лингвокультра также, как и общенациональная, является неоднородной. Она проявляется в разных формах: книжно-письменной, мультимедийной, традиционной. Последняя характеризуется тем, что порождается коллективными формами сознания, отражает и фиксирует патриархальный образ жизни, транслирует элементы архаики в ментальности и культуре. 
Старожильческая (традиционная по своей сути) сибирская ангарская лингвокультура сложилась в XVII-XVIII вв. под влиянием говоров и культурного кода европейского севера и северо-запада России, откуда были родом русские первопроходцы. Впоследствии их потомки составили костяк носителей старожильческих говоров. В XIX в. население Пиангарья прирастало в основном за счет переселенцев из центральных и отчасти юго-западных областей страны, а также ссыльных разных национальностей. Процесс формирования региональной макрообщности «сибиряки» растянулся на многие десятилетия и по некоторым данным не закончился до сих пор. В настоящее время понятие «сибиряк» мыслится как территориальное (тот, кто живет в Сибири); как региональное (тот, кто родился и живет в определенной части Сибири); как психологическое (тот, кто обладает особыми качествами: силой, крепким здоровьем, хорошей приспособленностью к жизни в суровых климатических условиях) и как надэтническое (тот, который с высокой степенью вероятности является русскоязычным представителем смешанного этноса, нечистокровный русский) (Жигунова, 1998; Малыгина, 2005). Потомки первых русских засельщиков Северного Приангарья носители сибирского старожильческого говора и сформировавшегося во второй половине XX в. ангарского региолекта - позиционируют себя как «настоящие русские сибиряки». Они не только унаследовали основные культурные традиции европейского севера России, но и в силу благоприятных для традиционных культур условий (отдаленность, относительная изолированность, экономические и культурные контакты с коренными народами Сибири), приумножили их.

Традиционная старожильческая лингвокультура Северного Приангарья выражается и транслируется преимущественно устными текстами повседневной и коллективно-личностной (ритуально-праздничной и фольклорной) коммуникации. Высокой лингвистической информативностью обладают устные персонифицированные рассказы нарративного типа о своей жизни, о родной деревне, народной педагогике, а также рассказы об охоте, рыбалке, необычных встречах и поразивших воображение рассказчика случаях. Вслед за У.Лабовым мы понимаем нарратив как «способ воссоздания прошлого опыта путём соотнесения вербальной последовательности предикаций с последовательностью событий, которые, как предполагается, имели место в действительности» (Labov 1982). Для устных нарративов характерны такие черты, как содержательность, цельность, связность, завершенность, интерпретативность, эмотивность, исповедальность и функциональная направленность. Их отличает композиционная 
простота, упрощение синтаксических конструкций, скупая образность (по сравнению с письменными повествованиями), эвиденциальность (т.е. засвидетельствованность).

В устном ангарском тексте выражается и аккумулируется жизненный опыт, знания и оценки различных групп населения Северного Приангарья, в частности, групп промыслово-природных (охотников, рыбаков, лесорубов и т.п.); ремесленно-бытовых (например, плотников, печников и т.п.); гендерно-возрастных (деревенских девушек и парней, стариков, детей); ритуальных (свах, свидетелей на свадьбах, крёстных и т.п.); сакрально-мистических (знахарей, гадалок, сибирских колдунов и ведьм), а также знания и представления социально-пограничных по отношению к коренному населению Северного Приангарья групп (бывших ссыльных, иноверцев, инородцев, приезжих, завербованных для работы в лесной и горнодобывающей промышленности). Особую группу текстов составляют нарративы коренных ангарцев о «своих» и «чужих». Тексты каждой из перечисленных групп представляют большой интерес для исследователей коммуникативного пространства Северного Приангарья и различных форм лингвокультуры этого региона. Однако наиболее информативными для достижения цели настоящего исследования являются устные тексты, эксплицирующие этнокультурные смыслы всего старожильческого социума, передающие собеседнику знания и принципы, на основе которых выбираются формы поведения, складываются культурные модели. Далее именно такие тексты будут рассмотрены нами как феномен традиционной лингвокультуры и важнейшее средство её трансляции.

\section{Методология (Methods)}

Корпус устных текстов, послуживших эмпирическим материалом настоящего исследования, формировался с помощью свободных и фокусированных интервью, а также посредством включенного наблюдения за повседневной коммуникацией коренных жителей Северного Приангарья. В него вошли преимущественно перволичные нарративы, устные рассказы фольклорного содержания (былички о «знатком человеке» и домовом), а также тексты делиберативного характера, т.е. тесты, в которых передаются размышления рассказчика о жизни раньше и сейчас, о верности и чести, о родине, воспитании детей и т.П., записанные автором на диктофон и видеокамеру в районах, относящихся к Северному Приангарью: Богучанском (в локальных пометах к иллюстративному 
материалу обозначается сочетанием Бг.), Кежемском (Кеж.) и в Мотыгинском (Мт.) районах Красноярского края в 2014-2018 годах. Дата записи текста указывается после ареальной пометы. Рассказчики - коренные жители районных центров, а также небольших таёжных посёлков и деревень - носители русского ангарского говора либо носители ангарского региолекта, сложившегося во второй половине XX века на базе русских старожильческих говоров, просторечия и народно-разговорной формы литературного языка. Исследование расшифрованных и отобранных текстов проводилось с применением частной методики коммуникативно-когнитивного метода, направленной на анализ ценностных доминант и эмотем избранных для анализа текстов, а также языковых средств их экспликации. В ходе исследования использованы также отдельные приёмы интерпретационного метода.

\section{Обсуждение (Discussion)}

Устные тексты, в которых отражены результаты переживания и осмысления мира, являются основным средством трансляции традиционной лингвокультуры и её ценностных доминант. Известно, что выражение «переживание мира» обозначает эмоционально-чувственное отношение к нему. Как справедливо отмечает И.В.Зыкова, - это «один из фундаментальных способов постижения человеком реальности, а также некий «способ» отражения в процессе познания действительности определенного психического состояния человека, выступающего как «событие» его собственной жизни» (Зыкова, 2017: 259). Переживание мира представителем старожильческой лингвокультуры эксплицируется различными средствами: эмотемами текста; лексическими средствами языка, которые передают оценку и выражают различные эмоции говорящего (эмотивы, коннотативы, экспрессивы, аффективы); единицами образного строя диалектной и народно-поэтической речи, а также вставными конструкциями, восклицаниями, риторическими вопросами и другими фигурами экспрессивного синтаксиса.

Отличительной особенностью устных текстов Северного Приангарья является их выраженная эмотивность. Во всех записанных нами устных текстах имеются как языковые, так и текстовые маркеры этого феномена. Особенно важно в свете решения поставленных в данной статье задач рассмотреть маркеры «осознанного переживания мира», т.е. рассмотреть средства экспликации моральных (нравственных) и эстетических чувств. Нравственные чувства - это 
«эмоциональная форма усвоенных личностью моральных принципов, норм, представлений» (о родине, совести, долге, чести, о себе и других людях и т.д.) «на основе ценностей моральных» (РСЭ, 1999). В устных ангарских текстах ярко выражены такие морально-нравственные чувства, как любовь к родной земле и сострадание к тем, кто вынужден был покинуть родное селение в связи с затоплением водами рукотворного Богучанского моря. Для эксплицикации этих чувств используются различные языковые и стилистические средства, в том числе разговорные фразеологические единицы, образность которых усиливает эмотивность текста в целом. «Таких, как Яркино, на планете одна. Таких Яркин боле нету. Ну и живите все хорошо, и мы будем хорошо жить, кто мешат. Бог-от всем дал-не однем. Мы живём, но и мы бережём сами, себе добывам. Много не добывам, никуды не продаем-сами для себя. А то, ну сделали электростанцию. Три Чубайса будут жить прекрасно, а вы как хотите. Сколь людей выселили! Сейчас бы меня отсель выселили, всё: я готов-умер. У барсука гнездо тепло, уютно, но орел в ём жить не будет, хоть кого ты ему делай. Орлу надо летать! И нам, так же нам. Почево эти гэсы? Почево цивилизация?» (Кеж.: Яркино, 2012). Этот текст убедительно показывает, что современная технократическая цивилизация не является ценностной доминантой коренного ангарца, проживающего в дальнем таёжном селении. Типичный член лингвокультурного сообщества воспринимает её как нечто враждебное привычному укладу жизни и природе. Эмоциональную реакцию на перемены, которые вызваны строительством ГЭС, передают эмотивы «страдать», «плакать», «плохо»; экспрессив «сильно изменилась», а также эмоционально-экспрессивное междометие «о»: «Люди-то страдали, их заставили и с мест с обжитых уехать. Плакали они все, не хотели. Кому где, кому в Кодинке дали квартирь, кто захотел, кому дали деньги, уехали, там где-то в Сосновоборске, в Дивногорске, в Красноярске разместились... Приезжали они тут, затопило и много... О-о-о! Здесь вообще Ангара изменилась. Раньше и купались, и глубоко было, и чиста вода, а щзас с ГЭСом вода стала холодна, купаться невозможно, вот стала мелкая... Вообще сильно изменилась, хуюе стала. Вот Ярки, где тут построили, эти комбинаты, там было столько ягод, грибов, там всё вырубили лес и построили всяки эти площуадки - всёе! Ничё не стало» (Бг.: Пинчуга, 2017).

Сибиряки-ангарцы, как правило, не испытывают кризиса этнокультурной идентичности, не пребывают в мировоззренческом вакууме. Рассуждая о своём селении, рассказчики демонстрируют патриотическое чувство «нравственной 
оседлости» (Д.С.Лихачев), негативно оценивают добровольный отъезд из родных мест. По отношению к человеку, покинувшему малую родину в поисках лучшей жизни, применяется коннотатив «предатель»: «Ну, по-своему я говорю. Как говорится, в Яркино родился, в Яркино и сгодился. Я родину свою не изменяю. Я не предатель. Не предатель. Которы уезжают, бросают. Вот, сяс, допустим, там у нас, директор работал всю жизнь, в Богучанах, на этой стороне, был леспромхоз, может, слыхала, Берёзовский? Там директор работал всю жизнь, он тоже уж умер, сюды приедет: «Ну, вы довели Яркино-то!». А ты куды уехал? Ты его возглавляй! Раз там, говорю, леспромхоз большой, сяло большо расстроилось. Ты бы не там работал, здесь бы работал! Сиди в сельсовете, командуй, планируй по путю. Нет, бросил, а потом, нас-то хулит, что мы, мол, довели дяревню. А кому дяржать-то её? Осталось сто человек, некорыстных. Ну, которы не изменили свою Родину. И вот, пять братовей, четыре брата все уехали, тоже предатели! Бросили своё сяло» (Кеж.: Яркино, 2018).

В устных ангарских текстах, наряду с патриотизмом, положительно оцениваются такие качества родственников и односельчан, как справедливость, требовательность, трудолюбие. Оценочные прилагательные и наречия, слова с положительной коннотацией характерны для нарративов о детстве, семье, родителях. Лексика с положительной коннотацией эксплицирует базовые чувства человека, которые определяют жизненные установки человека, направляют поведение, регулируют отношение к окружающей действительности. Прежде всего, речь идет о чувстве любви и уважения к близким родственникам, соседям, друзьям. Положительную оценочность текста актуализируют высказывания о том, что чувство уважения к кому-либо испытывает не только рассказчик, но и другие люди, вся крестьянская община: «А чё рассказать обо отще ... Бbлл хороший. Ну, как правило все отизы... У каждого свой отец хороший. Но если б брать даже на круг просто отцуов: он был человек верующий, он был справедливый, но строгой. Жёсткой даже будем говорить. Ну, жёсткой не скажешь, ну, строгой был. Доставалось нам постоянно. Разборов не было. Ране не воспитывали так, что чё-то где-то набедокурил или чё ли. Папа приходит, берёт ремень, всех сразу хвошиэт - все разборки! Разбирайтесь сами! Отхвостали всех - виноватого накажите ешио раз. Вот и всё. А когды были разборки? Кого? Это... И мы сами потом... Мы уже не даём творить, ты натворишь: щзас папа придёт, он ведь разбираться не будет, кто... Всех отхвостят. И тем самым, оно как бы хорошо. Мы-то уже дисииплину держим. Как в армиях возьми... 
В армиях, в зонах не начальство держит, а держит сам уклад жизни. Если б в армии, к примеру, один натворил и гоняют всех - ему больше не дадут натворить. Так и тут в семье. Ну, чё так рассказывать, рассказывать чё... Был... Было хорошо с ним всё: отличный был семьянин, отличный! Работяга! Вообшэ уважали его: в деревне уважсали, очень уважали, в колхозе уважали, на работе везде уважали» (Кеж.: Яркино, 2018). Если в мужчине ангарцы больше всего ценят трудолюбие, справедливость и строгость, то в женщине - хозяйственность и хлебосольство. Чувство восхищения этими качествами передается с помощью экспрессивов: «Их не было у Маруси ковров, это самое, таких, у неё были половики, по ним страшно было ходить, это были, как ковры, вот так вот были вытканы. И вот так вот, и такими вот и, в общеем, всякими кубиками были вытканы половики. ... А хлеб испекёт-вот такие булки! Ужас! О-ой, ой! Я даже с..., нет, не буду говорить, я щцас слюной подавлюсь, потому что мы, как приедем, все, сразу к ней. Она прямо ичеликом, вот это самое, все-все, ешьте-ешьте, у меня ещё, так что... И то черемуховые напекёт пироги, сверху сметаной намажет, м-м-м, то из брусники испекёт, о-ой, это же вообще объяданье было» (записано в г. Сосновоборске от переселенки из зоны затопления Богучанской ГЭС, 2014). В приведенном выше тесте эксплицируется не только эмоционально-чувственное отношение к конкретному человеку (Марусе), но и эстетическое переживание (... «половики...как ковры, вот так вот были вытканы»).

Высока плотность лексических средств, передающих чувство красоты, в текстах об Ангаре. Многие рассказчики используют перцептивные средства языка, которые помогают создать наглядный образ реки: «Ой, мила ты моя, святая матушка, вот поедем, вот ребята у меня, эту, когда кончили учиться, и их сразу направили в Гремученский лес на покос. И они уехали туда, а мы часто ездили с имя. У нас лодка была своя с мотором, сядем, поедем там все. Вот едешь, всё дно видно, вот всё, всё, всё, и чистое-пречистое, что сляза. А сейчас этого нету. Схожу если, вот бывало, по осени посмотреть на неё-мутная-мутная. Понастроили этих гэсок, ещеё говорят будут <строить>. Совсем загубили» (Бг:: Богучаны, 2017). Выражение эстетического чувства часто сочетается с выражением духовного переживания мира, с положительной оценкой «своих»: «У нас сколь гостей было, у нас много гостей отовсюду: из-за гранищы бывают гости большими группами и всякое. Но все, кто приезжат, однозначно говорили одно: экой деревни нету на свете. Но те люди, про которых я говорю, они объездили 
вообще весь мир полностью. Иу людоедов были, и везде, ну, полностью весь мир объездили. Такой, - говорят, - деревни нету, просто нету. И на самом деле мы замечам, и что особого в Яркино? Возьми Ерохта, Чадобеи - все закрылись деревни, в которых циивилизация, а они закрылись. Суды не приедешь, не доехать, а Яркино процветат, молодёжь едет. Стоит сюды к кому-то кто-то в гости приехать, - всё! Вон уже молодёжь какая-то приехала, они на следующее лето никуды не поедут, никуды, говорят: только в Яркино! Какое-то притяжение тако. И вот про этих людей, про которых говорю, про друзей, они говорят: мы её назвали, вашу деревню, «Райкино», рай на земле. Райкино - от слова рай. Райкино. Тут, говорят, на самом деле рай. Оно и на самом деле рай народу. Все, кто суды приехал, откуль-то они все тут остались. Народ всегды подсобит, народ всё-таки добрый» (Кеж.: Яркино, 2018). Эстетическое чувство красоты передают не только нарративные тексты, включающие описательные контексты о месте действия, но и тексты экспозиторного типа, в которых рассказчики подробно объясняют, как что-то сделать, приготовить. При этом может использоваться лексика с ласкательной коннотацией, например: «Шаньги делают с теста, потом намазывают на него... эту... делают... простоквашку... И замешивают и туда нальют. Наливка. А сверху сметанку, всё. И в печь. Они сверху-то, начинка вот... Оне красивеньки таки получатся! Я сказала, что вот сверху намажут, и всё, она, шанежка, прекрасная потом на вкус. А начинка... это уж у пирожков. Да и всякие пироги делали. Если, это, стряпают... Тесто такое... Для этого... питья с чаем... Пирожки там с ягодами со всякими разными. Там с черемухой и всякие... ягод же полно было. Все набирали же. Все делали. И такое-то ничё в магазине и ничё и не это, не брали. Ни повидло там, ничё. Вот всё это своё было. Ну, делали из рыбы пироги, там... Всё это делали. По-деревенски. Это была еда деревенская» (БГ.: Пинчуга, 2017). Все процитированные выше тексты содержат эмотемы, которые можно сгруппировать по их основным типам: а) эмотемы, основанные на знании прецедентных феноменов (рассказ о Яркино, который приезжие и сам рассказчик характеризуют как «Райкино»); б) эмотемы, основанные на передаче эмоционального состояния рассказчика (рассуждения рассказчиков о родном селе, рассказ о том, как пекут шанежки в родной деревне). Многие записанные нами воспоминания и рассуждения переселенцев из зоны затопления Богучанской ГЭС содержат эмотемы, основанные на представлениях о том, как не должно быть, что есть «не норма»: «Mы среди пожарищ жили. И старались, старались они (бригады вербованных 
и заключенных, которые «зачищали» ложе будущего Богучанского водохранилища - О.Ф.) жечь там, где живут люди. Вот, допустим, стоит ичельй квартал пустующий - они его не жгут. А будут жечь рядом, вот я тут живу рядом, со мной будут жечь дом, чтоб быстрей меня выжить. Это делалось специально, специально так выжигали. Жгли, жгли постоянно, рядышком. Цельми днями, ночами, у нас дом сточт, напротив был детский сад, наискосок был клуб... И в один день подожгли детский сад, клуб и ещуе один дом рядышком... Представляешь, детский сад здоровый, длинный такой, клуб такой высокий... и это всё в один раз зажгли. Вокруг дома у нас всё горело, представляешь <...> ну ведь можно в другом месте жечь. Да даже мы уедем- подожгите вы сразу всё, оно в один день всё сгорит. Нет! Они специиально будут жечь, хотя мы ещцё не уехали. <...>. Люди приезжали как-то, хотели взять брус, доски там, ну увезти в Кодинск. Не дали им с дома с этого, а на следующий день дом этот подожгли. Ну почему людям-то не отдать? Пусть увезут они. Вам какая разница? Лучше сожсём, но людям не дадим (записано от переселенки из зоны затопления Богучанской ГЭС в г. Сосновоборске в 2012 г.).

Отражение духовного и эстетического переживания мира в устном ангарском тесте неразрывно связано с экспликацией различных форм его осмысления. Для традиционных лингвокультурных сообществ типичны архетипическая, мифологическая и религиозная формы осмысления мира. В записанных нами текстах особенно выделяются архетипическая и мифологическая формы. По справедливому утверждению И.В. Зыковой «архетипы являются, по сути, первичным, определенным образом структурированным знанием, сформированным в глубинной ментальной стихии» (Зыкова, 2017: 270); они отражают обобщенный коллективный опыт, в котором воплощены представления о воине, охотнике, земном и небесном, своих и чужих, о добре и зле, о мужском и женском начале, о земле-матери. На пересечении социального и духовного опыта на протяжении нескольких поколений формировался стереотип «настоящего сибиряка» - воина, защитника, простого деревенского мужика, выросшего в условиях фронтира, готового защищать родную землю, малую и большую родину, ценою своей жизни. Устные рассказы о земляках, которые геройски воевали в годы Великой Отечественной войны или отличились особенной храбростью в Афганистане составляет важный пласт лингвокультуры Северного Приангарья. Служба в армии для коренного ангарца считается делом чести, воспитание будущего воина - первостепенным отцовским долгом. Ниже с незначительным 
сокращением приводится текст-рассуждение сорокалетнего мужчины, в котором выражены архетипы земли-матери и воина, который должен ее защищать: «Я вот тоже часто задаю себе вопрос, если война.... Победим мы сейчас? ... Хоть говорят, раньше Сталин там столько людей уничтожил, но люди шли в бой, даже зэки с зоны или, воры в законе шли, хотя они могли сидеть в зоне и ничего не делать, воры в законе, но они шли за свою родину, как говорится, есть родина - земля родная. Её надо отстаивать, эту землю. Мама - земля. Вот они из-за этого и или. Даже обиженные крестьяне раскулаченныле. Да. Как говорится, окромя власти советской есть земля родная. Вот так вот. Не, ну, но у нас ведь героев много и было, и есть, и будет много героев в России. Но, хоть говорят вот деревенские ребята, но я знаю: наши все пойдут. Я вот так, я уверен. И я как бы сына своего всегда настраиваю, что земля родная есть за неё надо воевать. Придётся - пойдёшь. Я даже, вот я вам не вру, даже погибнуть за неё готов, я ему (сыну) лично сам говорил:

\section{- Умри, но не опозорь.}

Вот я вам честно, руку на сердие ложу, так я говорил сыну, которому щуас вот 9 лет. Ну, а как без этого! Вот даже, вот так вот посмотришь телевизор: Москва, Санкт-Петербург, они как бы к нам-то относятся как? Мы - никто, мыл - колхоз, так? А кто вас отстоял в 41-м году? Сибирские войска, ребята, мужики. Сибирские пришли, вас и отстояли, так? А эти Пенкинь - все они кого отстоят? Ну, а чё не так, если они красятся? Они кого отстоят?! Они сразу ручки, лапки кверху. Опять же наши пойдут ребята: с колхозов, с совхозов, с периферии вас защцицать, так? Так оно и будет! <... > Наши-то ребята яркинские точно пойдут защищать, а городские я не знаю. Вот почему надо деревню держать. Самая наша, я считаю, вообще задача человеческая. Надо деревню удерживать, потому что она опора. Даже если мы сейчас уже поля не пашем. Действительно, если тянко будет, деревня родину-то защитит» (Кеж.: Яркино, 2018). Маркерами ценностных доминант этого текста выступают имена лингвокультурных концептов родина, родная земля, деревня, наши. Императивы «умри, но не опозорь», «надо деревню удерживать» - важнейшие ментальные установки, которые рассказчик передает слушателям, внушает их своему сыну.

Архетипическое осмысление мира приводит представителя традиционного лингвокультурного сообщества к установкам быть храбрым и осторожным одновременно, быть добытчиком и кормильцем семьи (архетип охотника). Охот- 
ничьему промыслу мальчиков обучают с детства, воспитывая хладнокровие и выдержку. В записанных нами охотничьих нарративах несколько раз повторяется сюжет, когда опытный охотник (обычно отец или дедушка) отправляет подростка в медвежью берлогу, чтобы тот привязал к лапе медведя верёвку, чтобы его вытащить наружу: «Ну, расскажу про первого медведя. Поехали в лес с дедушкой Митей. Ну, в общем, наш сворот, знаете, сгорел, был пожар в лесу. Но старик-то был, в этом месте охотился, он знат всё, дальше, говорит, проедем и всё. А дороги у нас на север, на восток идут, так? А мы дальше поехали, прямо на север поехали, прямо. Мы идём, идём, и мох накладенный, застеленный, и дед говорит: «Медведь накладал, не трогай, Федюшка». А собаки-то у нас, у него, не лаят. Вот трусливая собака! Хвост поджала <... >. Мы вырубили шесты, метра по два, чтобы на медведя берлогу идти, кресты делали. Один с одной стороны, другой с другой, караулят его, как бы вылез. А мы подошли, зарядили ружья. Медведь гад, то ли ему камни помешали, то ли глубоко не мог зарыться-то. Небольшой берлог сам-то, а землю всю замаскировал, чтобы не видно было. В одном месте клочочек оставил. Я потом гляжу-шевелится. Видишь, видишь? Так стреляй в него! Итак - «буиฺ» - стрельнули и всё, попали. Ну и вот. А после того вырубаешь шест, навинчиваешь медведя шерсть, тянешь, если он живой, лапой - бацฺ! А если не шевелится, так и убитьй значит. Ну попробовал. У них же опыт, у мужиков, а я пацаном-то был. И говорят: «Давай, Федюшка, на лапу надевай верёвку». Ну, показать боязнь неудобно как-то, потом смеяться будут в деревне. Но не струсил. Залез, лапу взял, верёвку надел. Вот так первого медведя и добывали (Кеж.: Заледеево, 2015).

Мифологическое мировосприятие является ещё одной типичной формой его осмысления. Жизнь коренного ангарца, живущего вдали от культурных центров, регулируется негласными правилами и табу, уходящими корнями в глубокое прошлое, например, в Богучанском районе существует запрет на произнесение слова «черный» применительно к природе, к «божьему свету»: «Тут рябина. Одну рябину, что сделал, дрова тут наклал, проволокой перекрутил и с той сторонь дрова, эти дрова посмотрели, она потом, проволока, в кору врезалась, она же растет, перерезала и высохла, а эта еще вот стоит. Черемуховый куст тут ещуе. Надо, наверное, скоро спилить ее. А что-то в этом году вообще нет ее, черемухи нету. Так-то черемухи каждый раз полно, висит красиво, чёрная. Темная. «Чёрное»не надо же говорить, надо говорить тёмная. Вот туча идёт, нельзя говорить, что чёрная, обязательно надо говорить тёмная. [А почему нельзя говорить? - Собир.] 
Это ранишние, раньше ещее старухи богомольнье говорили, где можно говорить. «Черный» можно говорить, только знать, где. А так лучше, всё лучше, скажи «тёмный». А вот чернылй, носки вот ... это чёрный, а если туча или такое вот природное, не надо говорить «чёрное». Тёмное! Туча идёт. Какая? Чёрная? Нет, тёмная идёт. Вот видишь» (Бг.: Невонка, 2014).

Характерной чертой мифологического осмысления мира являются анимализм и вера в возможность сверхъестественного воздействия человека на природу. Многочисленные факты одушевления природы обнаруживаем в рассказах об Ангаре, которую народное сознание воспринимает как «матушку», «роженицу», ей приписываются свойства человеческого характера: «Ангара жсестока к пьяным. У нас сколько людей перетонуло. Ангара не любит пьяных <...> (БГ.: Пинчуга, 2017); «Как река идёт, не то что корочку, а калачи кидали даже. Она, Ангара, как роженица-мать. Щитали, что её ломат, как она пойдёт. Чичас-то ледоколов нету на реке, она так растаиват и всё. А тогда кидали. Не только корочки, а калачи кидали. Ну, чтоб ей легче было иио идти, её щиштали как роженицу» (Бг.: Ангарский, 2017); «Ну, это хлеб опускали в воду. Вот, это, едешь, если, допустим, но у нас на островах сенокосы были, ездили почти каждый день, на проходных-то там и жили, а так-то, если едешь чё-нибудь, дак в воду кусочек макаешь, калачик либо там чё-нибудь и в лодке сидишь и вот ешь, и кажется вкуснее, чем, допустим, вот так ись. С ангарской водой, такая матушка Ангара была, а сейчас то... Матушка Ангара, поехали там, если чуть ветерок, либо чё-нибудь: «Ну, матушка Ангара, храни нас» (Бг.: Богучаны, 2017).

Мифологическое осмысление мира в лингвокультурном сообществе ангарцев тесно переплетено с религиозным. В рассказах о чудесном укрощении пожара или вызывании дождя всегда упоминается икона как важнейший атрибут обряда: «Так а дождя <когда> не было, собирались с иконами, ходили пели «Пресвята Мать Богородица». По улицам ходят, потом у кого маленький младенца, выносят в улииу, ложат, крестишь иконкой, потом все в Чадобец купаться. Ага. И люди, старухи, молодые, все. И дождь пойдёт. Угу. Бабушки ходили, мыл-то что, малолетки, ходили с ними. И вот надо было: родители выносят <младенца >, среди улицы ложат на дорогу, идут, иконой перекрестят и домой уносят». (Кеж.: Яркино, 2018).

Ангарцы-старожилы верят, что существует мистическая связь между человеком и природным миром, что «знаткой человек», обладающий особыми 
тайными знаниями, может останавливать грозу, или, напротив, вызывать дождь, влиять на поведение животных и судьбу людей: «Знаткой - это чё-то знает. Как у меня соседка была, мы в деревне жили, она говорила, если корову будешь держать, и она мне там говорила заговор, ну я, конечно, корову не собиралась держать, там за стену надо было, за корову, и говорить заговор и она никогда с места не вильнет ничего так. Чтобы корова возвращцалась это тоже. То есть младший старшего не должен учить, она мне говорила, бабушка, баба Анна. Надо чтобы старший был, вот я тебе мог, а ты мне ничем помочь не можешь, если ты меня научишь, я ничего использовать не могу (Бг.: Пинчуга, 2017). Рассказы о колдунах и знахарях, как правило, отличаются прямой или редупликативной эвиденциальностью (рассказчик либо ссылается на свой опыт общения со «знатким человекм», либо пересказывает услышанное, передает информацию со слов других лиц): «Hy, вот у нас mут в деревне, в Чунояре, была бабка одна. Она как бы вот это самое, ну, чё-то ей надо было то в стайку сходить испортить скотину, или ещё чё-нибудь. Вот тогда у нас, это баба рассказывала нам моя, говорит, что пришла, а овечка острижена. Всё, кто ночью вот значит. А утром... Кто-то её научил тут же какая-то бабка, говорит: «A ты возьми шерсть вот эту овечью на сковородку - и в печку в русскую». Горящая печка-то. И всё, говорит, она сама... И кто это сделал, она сама прибежит. Её будет тянуть, мутить и ей будет нехорошо, она сама придёт. Баба говорит: «Раз - вот она сама и является! Пришла: «Ой, чё-то я не могу, меня всю крутит, всю куда-то меня, вот это самое, мне так плохо, всё жнёт, всё крутит». Она говорит: «Так ты на что мою овечку-то стригла!». А та: «Ой-ой-ой-ой, бес попутал!». Hу, вот верь, не верь, да» (Бг.: Манзя, 2017).

Архаичные, исторически выработанные знания и представления о мире содержатся также в многочисленных быличках о домовых и других духах освоенного и неосвоенного человеком пространства. Естественное и сверхъестественное в представлении старожилов Северного Приангарья не разделяется демаркационной чертой: мифологические образы мыслятся как реально существующие: «Верю в домового, в домового верю. Муж, если вечером поест, то он крошки ему всегда оставит. Домовые есть злье, есть хорочие. Хорочие, когда ничё, греха никакого не делают. А злье могу душить. Мне один раз, знаете, был мороз, это я одна, муж на вахте был, ребятишек уже дома не было. Я лежу на диване и вот мне, понимаете, мне кто-то говорит: «Завтра будет 
тепло». И точно, встаю и завтра тепло! Но кто-то же мне говорил об этом. Но вот, пожалуйста! Поэтому я верю. Но вот, говорят, раньше, если корову даже это, ну, нехорошее делать, то хвост у неё как бы засосанный, то шкура да вот такая вот. Это дедушка-суседушка. Значит, ему плохо живется, или ругаются, или это, соседушка. Значит, ему плохо дома живётся, или ругаются, или это, то есть не дают ему спокоя. И он сердится, дедушка-суседушка. Утихомиривать надо. Ну вообще, говорят, надо молоко оставлять и конфетки по углам разложить, потому что он сладкоежка. Если домовой злой, то чё-то сами делаем не так, как надо. Сами зльее, видимо, правда? Ну, вот как вода открытая стоит, - ругаться нельзя. Вода принимает всё. Отсюда всё идёт. С годами всё равно человек другой становится, более спокойный, но если злой, то, наверное, более злой становится и завистливый (Бг.: Пинчуга, 2017).

\section{Заключение (Conclusion / Results)}

Устный ангарский текст во всем разнообразии его жанровых разновидностей является важнейшей единицей традиционной региональной лингвокультуры. В нём отражены существенные для региональной культуры смыслы и ценности (родина, честь, Ангара, семья, земляки и т.п.). В текстах манифестируется субнациональная идентичность коренных ангарцев (русские сибиряки), передаётся их жизненный опыт и нравственные установки.

Устные тексты Северного Приангаря отражают мифологическое мировосприятие старожилов региона, а также их окультуренные представления и знания о человеке, социуме, природе, инфернальном мире. Система оценок, образов, стереотипов, представленная в устном ангарском тексте, которая транслируется в процессе повседневной коммуникации следующим поколениям, обеспечивает устойчивость мировоззренческих представлений и способствует сохранению самобытности старожильческой сибирской культуры.

\section{Ссылки}

Афанасьева-Медведева, Г. В. (2007-2018). Словарь говоров русских старожилов Байкальской Сибири. В 20 томах, Санкт-Петербург, Иркутск, 1-20.

Афанасьева-Медведева, Г. В. (2011). Медвежий культ и отражение эго в устной народной прозе русских старожилов Восточной Сибири: семантика, сюжетно-мотивный фонд нарративов, номинации. Иркутск, 48 с. 
Банкова, Т. Б., Калиткина, Г. В. (2001). Традиционная культура старожилов Среднего Приобья в языковом коде (аспекты междисциплинарного исследования), В Межкультурная коммуникациия: теория и практика, 1, 120-132.

Васильев, В. К. (2018). Об архетипическом подходе к анализу женских образов-характеров (письменный и устный текст), В Сибирский филологический журнал, (3), 142-153.

Гольдин, В. Е. (2002). Доминанты традиционной сельской культуры, $B$ Аванесовский сборник: к 100-летию со дня рождения чл.-корр. АН СССР Р. И. Аванесова, Москва, Наука, 58-64.

Гольдин, В. Е., Крючкова, О. Ю. (2010). Русская диалектология. Коммуникативный, когнитивныий и лингвокультурологический аспекть, Саратов, Наука, $120 \mathrm{c}$.

Гынгазова Л. Г., Иванцова Е. В. (2015). Ключевые ценности крестьянской культуры в высказываниях языковой личности о себе, В Язык в пространстве речевых культур: к 80-летию В. Е. Гольдина, Москва, Саратов, 36-45.

Жигунова, М. (1998). Этносоциология русских Сибири: проблемы современной идентичности, В Этносочиильные прочессы в Сибири: тематический сборник, Новосибирск, 191-195.

Зыкова, И. В. (2017). Метаязык лингвокультурологии: константы и варианmbl. Москва, Гнозис, 259 с.

Кайзер, К. В., Фельде, О. В. (2018). Устные рассказы о «знатких людях» как нарративный жанр, В «Язык и культура: сборник статей XXVIII Международной конференции, 40-46.

Карасик, В. И. (1996). Культурные доминанты в языке. Языковая личность: культурные конщептыл. Волгоград-Архангельск, Перемена, 259 с.

Красных, В. В. (2002). Этнопсихолингвистика и лингвокультурология: курс лекций. Москва, Гнозис, 284 с.

Красных, В. В. (2013) Грамматика лингвокультуры, или что держит языковую картину мира, В Экология языка и коммуникативная практика, (1), 133-141.

Леонтьев, А. А. (1993). Языковое сознание и образ мира, В Языковое сознание: парадоксальная раџиональность, Москва, 16-22.

Малыгина, И. В. (2005). Этнокультурная идентичность: структура и исторические формы, В Вестник Московского государственного университета культуры и искусства, (2), 13-20.

Российская соииологическая эничиклопедия. Москва, Норма-Инфра-М, 672 с. 
Смирнов, Е. С. (2008). Репрезентация концепта «беглые» в ангарской лингвокультуре (на материале устных рассказов и интервью коренных жителей Северного Приангарья), В Мир науки, культуры, образования, 5 (72), 474-477.

Терентьева, Е. В. (2013). Лингвокулькультурное пространство Волгоградской области, В Вестник Волгоградского государственного университета, (2), 184-188.

Федоров, М. А. (2014). Термин «лингвокультура» в аспекте теории культуры, В Вестник Бурятского государственного университета, 6(2), 84-86.

Фельде, О. В. (2014). Ангарская лингвокультура в лексикографическом освещении, В Проблемы истории, филологии, культуры, Москва-МагнитогорскНовосибирск, 3(45), 190-192.

Andrade, R. (1995). The development of cognitive anthropology. Cambridge, Cambridge Univ. Press, 1995, 288 p.

Casson, R.W. (1981). Language, culture and cognition: Antropological perspeclives. New York, Macmillan, 489 p.

Labov, W. (1982). Speech Actions and Reactions in Personal Narratives, In Analyzing Discourse: Text and Talk. Washington, Georgetown University Press, 219-247.

\section{References}

Afanas'eva-Medvedeva, G.V. (2007-2017). Slovar' govorov russkikh starozhilov Baikal'skoi Sibiri. V 20 tomakh [Dictionary of Dialects of Russian Old-Timers of Baikal Siberia. In 20 Volumes]. Saint Petersburg, Irkutsk, 1-19.

Afanas'eva-Medvedeva, G.V. (2011). Medvezhii kul't $i$ otrazhenie ego v ustnoi narodnoi proze russkikh starozhilov Vostochnoi Sibiri: semantika, siuzhetno-motivnyi fond narrativov, nominatsii [Bear Cult and Its Reflection in the Oral Folk Prose of Russian Old-Timers of Eastern Siberia: Semantics, Plot-Motive Fund of Narratives, Nominations]. Irkutsk, $48 \mathrm{p}$.

Andrade, R. (1995). The Development of Cognitive Anthropology. Cambridge, Cambridge Univ. Press, 1995, 288 p.

Bankova, T.B., Kalitkina, G.V. (2001). Traditsionnaya kul'tura starozhilov Srednego Priob'ia v iazykovom kode (aspekty mezhdistsiplinarnogo issledovaniia) [Traditional Culture of Old-Timers of the Middle Ob in the Language Code (Aspects of Interdisciplinary Research)]. In Mezhkul'turnaia kommunikatsiia: teoriia i praktika [Intercultural communication: theory and practice], 1, 120-132.

Casson, R.W. (1981). Language, Culture and Cognition: Anthropological perspectives. New York, Macmillan, 489 p. 
Fedorov, M.A. (2014). Termin "lingvokul'tura" v aspekte teorii kul'tury [The Term 'Linguoculture' in the Aspect of the Theory of Culture]. In Vestnik Buriatskogo gosudarstvennogo universiteta [Scientific journal of Buryat State University], 6 (2), 84-86.

Fel'de, O.V. (2014). Angarskaia lingvokul'tura v leksikograficheskom osveshchenii [Angara Linguistic Culture in Its Lexicographic Aspect]. In Problemy istorii, filologii, kul'tury [Problems of History, Philology and Culture], Moscow-Magnitogorsk-Novosibirsk, 3 (45), 190-192.

Gol'din, V.E. (2002). Dominanty traditsionnoi sel'skoi kul'tury rechevogo obshcheniia [Dominants of Traditional Rural Culture of Speech Communication]. In Avanesovskii sbornik: $k$ 100-letiiu so dnia rozhdeniia chl.-korr. AN SSSR R.I. Avanesova [Avanesov's Collection: the 100th Anniversary of the Birth of Corresponding member.corr. USSR Academy of Sciences R.I. Avanesov], Moscow, Nauka, 58-64.

Gol'din, V.E., Kriuchkova O.Iu. (2010). Russkaia dialektologiia. Kommunikativnyi, kognitivnyi i lingvokul'turnyi aspekty [Russian Dialectology. Communicative, Cognitive and Linguocultural Aspects]. Saratov, Nauka, 120 p.

Gyngazova, L.G., Ivantsova, E.V. (2015). Kliuchevye tsennosti krest'ianskoi kul'tury v vyskazyvaniiakh dialektnoi iazykovoi lichnosti o sebe [The Core Values of the Peasant Culture in the Statements of the Dialect Language Personality About Himself]. In Iazyk v prostranstve rechevykh kul'tur: K 80-letiiu V.E. Gol'dina [Language in the Space of Speech Cultures: to the 80th Anniversary of V.E. Goldin], Moscow, Saratov, Amirit, 36-45.

Kaizer, K.V., Fel'de, O.V. (2018). Ustnye rasskazy o “znatkikh liudiakh” kak narrativnyi zhanr [Oral Stories About Wizards and Witch Doctors as a Narrative Genre]. In Iazyk i kul'tura: Sbornik statei XXVIII Mezhdunarodnoi konferentsii [Language and Culture: Collection of Articles of the XXVIII International Conference], 40-46.

Karasik, V.I. (1998). Cultural Dominants in Language. Linguistic Personality: Cultural Concepts. Volgograd-Arkhangelsk, 259 p.

Krasnykh, V.V. (2002). Etnopsikholingvistika i lingvokul'turologiia: kurs lektsii [Ethnopsycholinguistics and Linguistic Culturology: a Course of Lectures], Moscow, Gnozis, 284 p.

Krasnykh, V.V. (2013). Grammatika lingvokul'tury, ili chto derzhit iazykovuiu kartinu mira? [Grammar of Linguoculture, or What Holds the Linguistic Picture of the World?]. In Ekologiia iazyka i kommunikativnaia praktika [Ecology of Language and Communicative Practice], (1), 133-141. 
Labov, W. (1982). Speech Actions and Reactions in Personal Narratives. In Analyzing Discourse: Text and Talk. Washington, Georgetown University Press, 219-247.

Leont'ev, A.A. (1993). Iazykovoe soznanie i obraz mira [Language Consciousness and Image of the World]. In Iazyk $i$ soznanie: paradoksal'naia ratsional'nost' [Language and Consciousness: Paradoxical Rationality], Moscow, 16-22.

Malygina, I.V. (2005). Etnokul'turnaia identichnost': struktura i istoricheskie formy [Ethnocultural Identity: Structure and Historical Forms], In Vestnik Moskovskogo gosudarstvennogo universiteta kul'tury i iskusstv [Scientific Journal of the Moscow State University of Culture and Arts], (2), 13-20.

Rossiiskaia sotsiologicheskaia entsiklopediia [Russian Sociological Encyclopedia]. (1998). Moscow, Norma-Infra-M, 672 p.

Smirnov, E.S. (2008). Reprezentatsiia kontsepta “beglye” v angarskoi lingvokul'ture (na materiale ustnykh rasskazov i interv'iu korennykh zhitelei Severnogo Priangar'ia) [Representation of the concept "runaway" at the Angarsk Linguistic Culture (as Exemplified by Oral Stories and Interviews of the Indigenous People of the North Angara Region)]. In Mir nauki, kul'tury, obrazovaniia [World of Science, Culture, Education], 5 (72), 474-477.

Terent'eva, E.V. (2013). Lingvokul'turnoe prostranstvo Volgogradskoi oblasti [Linguocultural Space of the Volgograd Region]. In Vestnik Volgogradskogo gosudarstvennogo universiteta [Scientific Journal of Volgograd State University], 2, 184-188.

Vasil'ev, V.K. (2018). Ob arkhetipicheskom podkhode k analizu zhenskikh obrazov-kharakterov (pis'mennyi i ustnyi tekst) [On the Archetypal Approach to the Analysis of Female Character Images (Written and Oral Text)]. In Sibirskii filologicheskii zhurnal [Siberian Philological Journal], 3, 142-153.

Zhigunova, M. (1998). Etnosotsiologiia russkikh Sibiri: problemy sovremennoi identichnosti [Sociology of the Russians of Siberia: Problems of Modern Identity]. In Etnosotsial'nye protsessy v Sibiri: tematicheskii sbornik [Ethnosocial Processes in Siberia: a Case Collection], Novosibirsk, 191-195.

Zykova, I.V. (2017). Metaiazyk lingvokul'turologii: konstanty i varianty [Meta-language of Linguoculturology: Constants and Variants]. Moscow, Gnozis, 259 p. 


\section{Устный текст как транслятор \\ старожильческой лингвокультуры \\ Северного Приангарья}

О.В. Фельде

Сибирский федеральный университет Россия, 660041, Красноярск, пр. Свободный, 79

В статье рассматривается устный сибирский текст как важнейшая единица региональной лингвокультуры - иелостного и одновременно гетерогенного лингвокогнитивного феномена, детерминированного культурными кодами и субкодами (антропоморфным, биоморфным, теологическим, мифологическим), пространственными координатами, иенностными доминантами и социальным опытом локального сообщества. Выявляются и анализируются языковые средства, эксплицирующие эмоционально-чувственные, этические, эстетические переживания сибиряков-ангарцев, а также приёмы и средства экспликации мифологического осмысления мира. Исследование проводится на материале устных текстов, преимущественно персонифицированных нарративов, записанных автором статьи в условиях комплексных фольклорно-диалектологических экспедищий в деревни Северного Приангарья, которые были основаны русскими в XVII-XVIII вв. Делается вывод о том, что устный ангарский текст отражает окультуренные представления и знания русских сибиряков о человеке, социуме, природе, инфернальном мире. Система оиенок, образов, стереотипов, представленная в устном ангарском тексте, транслируемая в процессе повседневной коммуникации следующим поколениям, обеспечивает устойчивость мировоззренческих представлений и способствует сохранению самобытности старожильческой сибирской культуры.

Ключевые слова: Северное Приангарье, региональная лингвокультура, культурный код, устный текст, нарратив, эмотема, эмотив, аффектив, коннотатив, экспрессив, образ мира, переживание мира, осмысление мира.

Исследование выполнено при финансовой поддержке РФФИ, Правительства Красноярского края, Красноярского краевого фонда поддержки научной и научно-технической деятельности в рамках научного проекта № 17-14-24008 «Электронный текстовый корпус лингвокультуры Северного Приангарья».

Научная специиальность: 10.00.00 - филологические науки. 